Revista Brasileira de Agricultura Irrigada v.11, no.8, p. 2141 - 2151, 2017

ISSN 1982-7679 (On-line)

Fortaleza, CE, INOVAGRI - http://www.inovagri.org.br

DOI: $10.7127 /$ rbai.v11n800701

Protocolo 701.17 - 14/06/2017 Aprovado em 17/10/2017

\title{
ACÚMULO DE FITOMASSA DE CULTIVARES DE ALFACE HIDROPÔNICA SUBMETIDAS À SALINIDADE
}

\author{
Rafaela Felix Basílio Guimarães ${ }^{1}$, Ronaldo do Nascimento ${ }^{2}$, Jailton Garcia Ramos ${ }^{3}$, Sabrina \\ Cordeiro de Lima ${ }^{4}$, José Alberto Ferreira Cardoso ${ }^{5}$, Daniele Ferreira de Melo ${ }^{6}$
}

\begin{abstract}
RESUMO
O objetivo deste estudo foi avaliar os efeitos de diferentes níveis de salinidade na acumulação de fitomassa de duas cultivares de alface sob cultivo hidropônico. $\mathrm{O}$ experimento foi realizado em um ambiente protegido na Universidade Federal de Campina Grande (UFCG), Campus I, durante o período 01 a 22 de setembro de 2016. O delineamento experimental foi inteiramente casualizado (DIC), em esquema fatorial $2 \times 4$, duas variedades de alface, Valentina (C1) e Alcione (C2) e quatro níveis de condutividade elétrica da solução nutritiva $\left(\mathrm{CE}_{S N}\right)\left(1,6,3,6,5,6\right.$ e 7,6 dS m$\left.{ }^{-1}\right)$, totalizando 8 tratamentos com 3 repetições cada, resultando em 24 unidades experimentais. As variáveis analisadas foram o número de folhas, fitomassa fresca e seca de folhas, caule e raízes, e fitomassa total da parte aérea. Observou-se que as variáveis fitomassa fresca das folhas e do caule, e fitomassa seca das folhas foram significativamente afetadas pelos níveis de salinidade, apenas a fitomassa seca das folhas e a fitomassa fresca das raízes diferiram entre as cultivares. O ponto de máxima produção de matéria fresca das folhas foi observado na $\mathrm{CE}_{\mathrm{SN}}$ de $3,5 \mathrm{dS} \mathrm{m}^{-1}$, o acúmulo de fitomassa decresceu $31,48 \%$ para $\mathrm{CE}_{\mathrm{SN}}$ de 7,6 dS m${ }^{-1}$. Houve interação entre os fatores apenas para a massa seca da folha.
\end{abstract}

Palavras-chave: água salina, vegetais, Lactuca sativa $L$.

\section{PHYTOMASS ACCUMULATION OF HYDROPONIC LETTUCE CULTIVARS SUBMITTED TO SALINITY}

\begin{abstract}
The objective of this study was to evaluate the effects of different levels of salinity on the phytomass accumulation of two curly lettuce cultivars under hydroponic cultivation. The experiment was carried out in a protected environment in Universidade Federal de Campina Grande (UFCG), Campus I, during the period from 01 to 22 September 2016. The experimental design was completely randomized (DCR), in factorial scheme $2 \times 4$, two varieties of lettuce, Valentina (C1) and Alcione
\end{abstract}

\footnotetext{
${ }^{1}$ Mestranda em Irrigação e drenagem, UFCG, e-mail: rafaellafelix_@ hotmail.com

${ }^{2}$ Doutor em agronomia, Prof. da UFCG, e-mail: ronaldo@ deag.ufcg.edu.br

${ }^{3}$ Mestrando em Irrigação e drenagem, UFCG, e-mail: jailtonbiossistemas@gmail.com

${ }^{4}$ Mestranda em Irrigação e drenagem, UFCG, e-mail: sabrina.lcordeiro@ hotmail.com

${ }^{5}$ Doutorando em irrigação e drenagem pela UFCG, Prof. do IFTO, e-mail: jalbertofcardoso@gmail.com

${ }^{6}$ Mestranda em construções rurais e ambiência, UFCG, e-mail: danimelo.ufcg@ hotmail.com
} 
(C2) and four levels of salinity $\left(1,6,3,6,5,6 \mathrm{e} \mathrm{7,6} \mathrm{dS} \mathrm{m} \mathrm{m}^{-1}\right)$, totaling 8 treatments with 3 replicates each, resulting in 24 experimental units. The analyzed variables were the number of leaves, fresh and dry phytomass of leaves, stem and roots, and total aerial part phytomass. It was observed that the variables of the fresh phytomass of the leaves, fresh of the stem and dry matter phytomass were significantly affected by salinity levels, only the dry phytomass of leaves and fresh root phytomass differed between cultivars. The point of maximum yield of fresh leaf matter was observed in the $\mathrm{EC}_{\mathrm{SN}}$ de 3,5 $\mathrm{dS} \mathrm{m}{ }^{-1}$ the phytomass accumulation decreased by $31.48 \%$ for $\mathrm{EC}_{\mathrm{SN}} 7,6 \mathrm{dS} \mathrm{m}^{-1}$. There was interaction between the factors only for the leaf dry phytomass.

Keywords: saline water, vegetable, Lactuca sativa L.

\section{INTRODUÇÃO}

A alface (Lactuca sativa L.) se destaca por ser a folhosa mais consumida no Brasil e a $3^{\text {a }}$ hortaliça em maior volume de produção, movimentando anualmente, em média, $\mathrm{R} \$ 8$ bilhões apenas no varejo, com uma produção de mais de 1,5 milhão de toneladas ao ano (ABCSEM, 2013). Em sistema hidropônico é a hortaliça mais produzida no Brasil por meio da técnica do filme nutriente (NFT) (PAULUS et al., 2010). Nesse sistema, o solo ou substrato é substituído por uma solução nutritiva que fornece todos os nutrientes essenciais para o crescimento e o desenvolvimento da planta. Ainda segundo SANTOS (2012) o cultivo hidropônico, em termos de produtividade, é muito superior ao cultivo convencional, podendo alcançar uma produtividade de 46 toneladas por hectare, enquanto a alface cultivada no solo a produtividade gira em torno de 18 toneladas por hectare. Logo, o cultivo hidropônico se apresenta como uma alternativa à agricultura no semiárido brasileiro, região caracterizada por apresentar escassez hídrica, irregularidade de distribuição das chuvas (CAVALCANTE et al., 2011), clima e natureza geológica que contribuem para o processo de salinização das águas (Cruz \& Melo 1969), características essas que inviabilizam uso dessas fontes hídricas como insumo para agricultura irrigada convencional, pois pode provocar segundo SILVA et al., (2009) modificações morfológicas, estruturais e metabólicas nas plantas, comprometendo o crescimento, a redução do ciclo das culturas e produtividade.

No entanto, trabalhos realizados com alface hidropônico utilizando solução nutritiva salinizada (Soares, 2007) constatou que em sistema NFT houve uma maior tolerância à salinidade em relação ao plantio no solo, pois neste tipo de cultivo o potencial mátrico é nulo, estabelecendo um maior potencial total de água disponível, facilitando deste modo a absorção de água pelas plantas.

Diante desta perspectiva, estudos acerca desta problemática vêm sendo desenvolvidos com objetivo de viabilizar o uso de águas salinizadas como insumo para o cultivo hidropônico, onde a principal hortaliça que tem sido enfoque de pesquisas é a alface (PAULUS et al.; 2010; SANTOS et al., 2010; SOARES et al., 2010; ALVES et al., 2011; MACIEL, 2012).

RODRIGUES et al., (2015), em um estudo desenvolvido em ambiente protegido no Espírito Santo verificou uma diminuição linear no desenvolvimento de cultivares de alface quando submetidos a níveis crescentes de sais na água de irrigação. OLIVEIRA et al., (2011) também constatou redução no desenvolvimento das plantas com o aumento da salinidade da água, mas que o nível de resposta variou entre as cultivares estudadas.

Diante desse contexto, objetiva-se avaliar o efeito de diferentes níveis de salinidade no acúmulo de fitomassa de duas cultivares de alface crespa, sob cultivo hidropónico.

\section{MATERIAL E MÉTODOS}

O experimento foi desenvolvido na Universidade Federal de Campina Grande (UFCG), situada no município de Campina Grande, PB sob as coordenadas geográficas de $7^{\circ} 13^{\prime} \mathrm{S}$ e $35^{\circ} 53^{\prime} \mathrm{O}$ e altitude de 550m (Figura 1). 


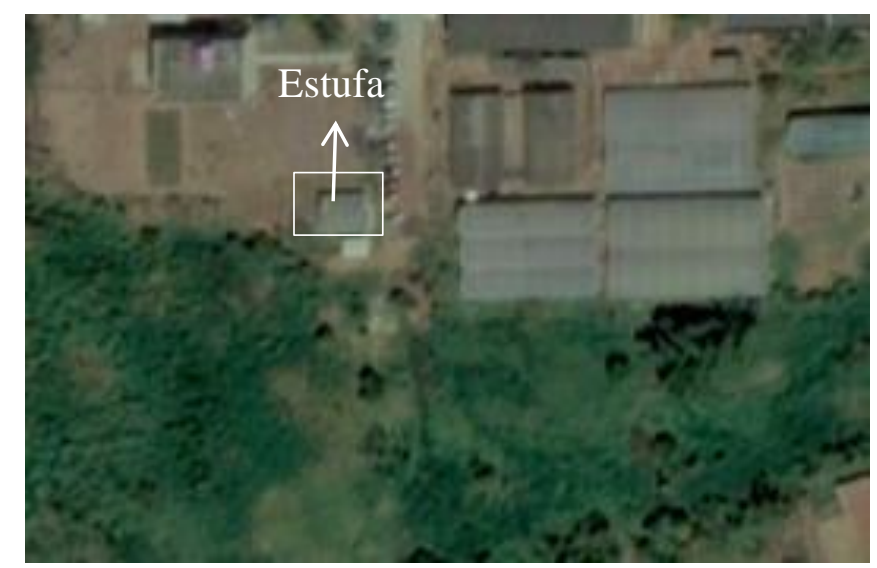

Figura 1. Localização do local do experimento na UFCG.

O experimento foi desenvolvido durante o período de 01 a 22 de setembro de 2016 , conduzido em estufa convencional, que possui estrutura em arcos galvanizados com dimensões de $6,0 \mathrm{~m}$ de largura $\mathrm{x} 10 \mathrm{~m}$ de comprimento e pé-direito de 3,00m, coberta com filme plástico transparente e laterais envolvidas com telado (Figura 2) que permitem a passagem parcial do vento, amenizando a temperatura interna.

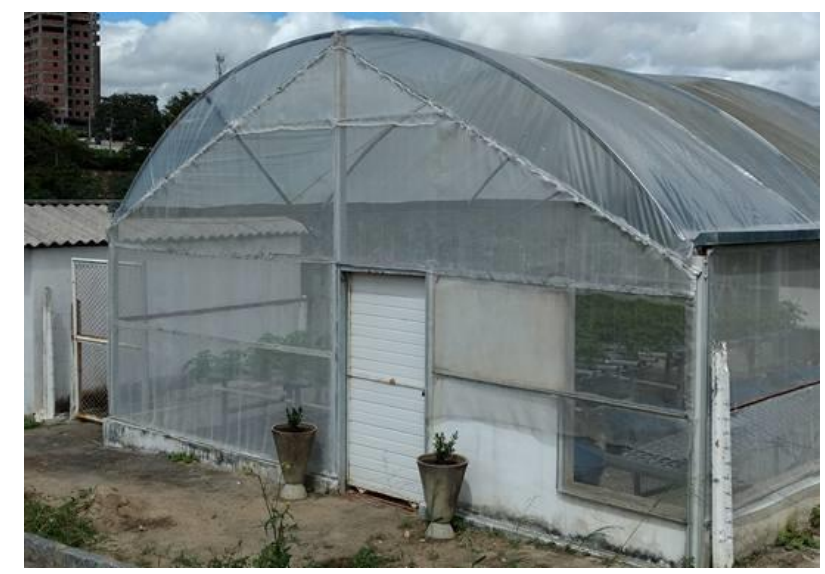

Figura 2. Visão geral da estufa onde o projeto foi desenvolvido.

No interior da estufa possui quatro bancadas de plantio hidropônico em sistema NFT, espaçadas uma das outras em $0,80 \mathrm{~m}$, com altura inicial de $1,10 \mathrm{~m}$ e declividade de 2 $\%$. Os perfis são espaçados em $0,10 \mathrm{~m} \mathrm{e}$ apresentam comprimento de 4,0 $\mathrm{m}$. Os perfis referentes a cada tratamento são interligados a um reservatório de plástico rígido com capacidade de 300 litros, onde se encontra armazenada a solução nutritiva (Figura 3).

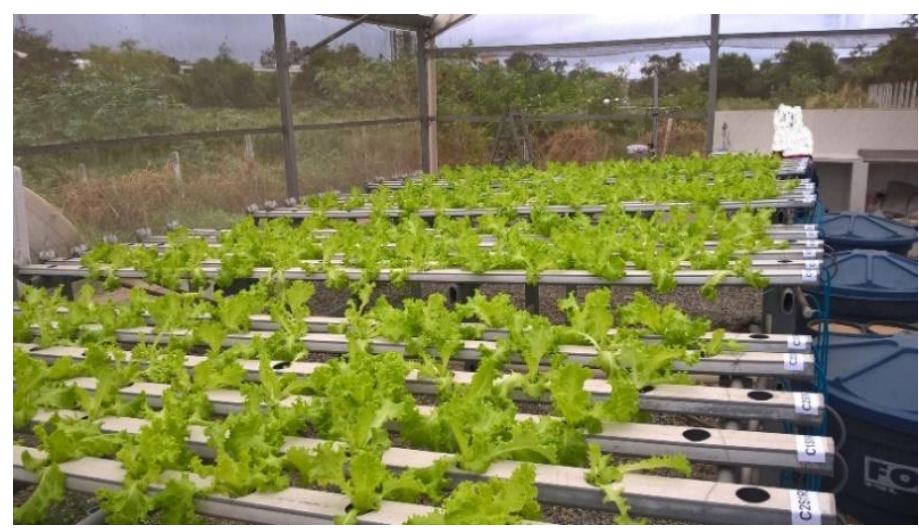

Figura 3. Visão geral do sistema hidropônico. 
A vazão da solução nos canais e a potência da bomba foi determinada considerando a recomendação de (FURLANI et al., 2009). Cada bomba se conecta a um temporizador analógico, ligado à energia elétrica, para manter a solução circulando automaticamente. Os temporizadores foram programados para irrigações a cada 15 minutos durante o dia, e intervalos de uma hora no período noturno.

Utilizou-se o delineamento experimental inteiramente casualizado (DIC), onde os fatores estudados foram arranjados em esquema fatorial $4 \times 2$, sendo duas variedades de alface, a Valentina (C1) e a Alcione (C2) submetidas a quatro níveis de condutividade elétrica da solução nutritiva (1,6, 3,6, 5,6 e 7,6 $\mathrm{ds} \mathrm{m}^{-1}$ ), com 3 repetições (cada repetição é representada por um perfil).

Os perfis foram etiquetados com cada tratamento e sua respectiva repetição, onde realizou-se o transplantio de 12 mudas de alface espaçadas em $0,25 \mathrm{~m}$ entre plantas. Ressalta-se que foi deixada como bordadura duas plantas de cada perfil, a primeira e a última, com o intuito das plantas terem o mesmo nível de competição por luz e espaço para o seu crescimento normal.

A variedade utilizada no experimento foi do segmento alface crespa, onde foram utilizadas as cultivares Alcione e Valentina. As sementes foram semeadas em espuma fenólica previamente lavada com água corrente, para eliminar possíveis resíduos remanescentes de sua fabricação, o desenvolvimento das mudas ocorreu na estrutura hidropônica da Hortifrut Sempre Verde, localizado no município de Lagoa Seca - PB, onde as placas foram inicialmente umedecidas somente com água de chuva, e posteriormente com solução nutritiva diluída em $50 \%$.

As mudas foram mantidas em uma estrutura coberta com tela tipo sombrite e em seguida as plântulas obtidas foram transferidas para bancadas de desenvolvimento (berçário), e quando alcançaram de 6 a 8 folhas definitivas (aproximadamente 30 dias), foram transportadas para o campus I da UFCG, onde se realizou o transplantio para bancada hidropônica definitiva.
O preparo e manejo da solução nutritiva seguiram a recomendação de (FURLANI et al., 1999) para todos os tratamentos. A formulação utilizada para o preparo da solução foi o composto Hidrogood Fert, que contém todos os macronutrientes e micronutrientes necessários para o bom desenvolvimento da cultura. $\mathrm{O}$ composto foi adicionado à água junto com o Nitrato de Cálcio e Ferro quelatizado, também da Hidrogood, e a preparação foi realizada conforme recomendações do fabricante.

Para o tratamento S1, a solução foi preparada com água da chuva, devido a baixa salinidade que esta apresenta, tendo em vista que este tratamento trata-se da testemunha $\mathrm{e}$ portanto, necessita da menor condutividade elétrica da solução nutritiva $\left(\mathrm{CE}_{\mathrm{SN}}\right)$, o tratamento $\mathrm{S} 2$ foi preparado com água do sistema de abastecimento local de Campina Grande - PB, proveniente da Companhia de Água e Esgoto da Paraíba - CAGEPA, sendo ainda necessário, a adição de $\mathrm{NaCl}$ (cloreto de sódio) para alcançar o valor de CEs proposto na pesquisa.

Houve monitoramento diário das soluções para garantir a condutividade elétrica correta para cada tratamento, sendo realizada a verificação através de um condutivímetro de bancada modelo Mca 150, duas vezes ao dia, e se necessário, a mesma era ajustada através da diluição do tratamento com uma solução nutritiva de ajuste, previamente preparada com água de chuva e armazenada em reservatório extra, conforme recomendação de (FURLANI et al., 1999), ou através da adição de $\mathrm{NaCl}$, caso fosse necessário concentrar mais a solução.

Realizou-se também o controle diário do $\mathrm{pH}$, através de um pHmetro de bancada modelo LUCA-210, para que o mesmo fosse mantido entre 5,5 e 6,5 (devido se tratar do intervalo ótimo para absorção de nutrientes), ajustando-o quando necessário, através de uma solução base composta por hidróxido de sódio ou uma solução ácida composta por ácido sulfúrico.

Os valores de temperatura e umidade relativa do ar (máximas e mínimas) foram verificados e anotados diariamente através de higrômetro digital. 
A coleta de dados foi realizada 14 dias após transplantio, sempre no mesmo horário, onde utilizou-se três unidades de alface referente a cada repetição.

As variáveis analisadas foram número de folhas, fitomassa fresca e seca das folhas, do caule e das raízes, e a fitomassa da parte aérea total. O número de folhas (NF), foi determinado pela contagem de folhas verdes, desprezando-se as amareladas e/ou secas; a fitomassa foi determinada pela pesagem em balança de precisão, de cada parte separadamente, onde a massa fresca da parte aérea foi obtida pela soma das folhas e do caule.

Os resultados foram submetidos ao teste de normalidade, onde verificou-se distribuição normal dos dados, em seguida realizou-se a análise de variância pelo teste $\mathrm{F}$ em $5 \%$ de probabilidade ( $\mathrm{p}<0,05)$; Quando significativo, para as variáveis qualitativas, as médias foram comparadas pelo teste de Tukey $(\mathrm{p}<0,05)$. Para variáveis quantitativas, os dados foram submetidos ao teste de regressão ( $p<0,05)$. Na análise utilizou-se o software SISVAR (FERREIRA, 2014).

\section{RESULTADOS E DISCUSSÃO}

A análise de variância dos dados referente a coleta aos 14 dias após transplantio (DAT) é observada na Tabela 1, em que verificou-se efeito significativo dos níveis de salinidade (NS) sob as variáveis fitomassa fresca e seca das folhas e fitomassa fresca do caule. No entanto, o número de folhas, a fitomassa seca do caule, fitomassa fresca e seca das raízes não foram afetadas significativamente pelos diferentes níveis de salinidade. As cultivares (C) estudadas diferiram significativamente entre si para as variáveis fitomassa seca das folhas e fitomassa fresca da raiz. E houve efeito da interação (NS x C) apenas para fitomassa seca das folhas.

Tabela 1 -Análise de variância referente às variáveis fitomassa fresca folhas (FFF), fitomassa seca folha (FSF), fitomassa fresca caule (FFC), fitomassa seca caule (FSC), fitomassa fresca raiz (FFR) e fitomassa seca raiz (FSR) aos 14 DAT

\begin{tabular}{|c|c|c|c|c|c|c|c|c|}
\hline \multirow{2}{*}{ FV } & \multirow{2}{*}{ GL } & \multicolumn{7}{|c|}{ Quadrados Médios } \\
\hline & & $\mathrm{NF}$ & FFF & FSF & FFC & $\mathrm{FSC}$ & FFR & FSR \\
\hline NS & 3 & $22.444^{\mathrm{ns}}$ & $6588.15 * *$ & $3.8797 * *$ & $74.4346 * *$ & $0.0671^{\mathrm{ns}}$ & $129.65^{\mathrm{ns}}$ & $0.1097^{\mathrm{ns}}$ \\
\hline $\mathrm{C}$ & 1 & $28.1666^{\mathrm{ns}}$ & $2101.69^{\mathrm{ns}}$ & $0.8288 * *$ & $14.3067^{\mathrm{ns}}$ & $0.0600^{\mathrm{ns}}$ & $551.61^{* *}$ & $0.2204^{\mathrm{ns}}$ \\
\hline $\mathrm{NS} \times \mathrm{C}$ & 3 & $1.0555^{\mathrm{ns}}$ & $1133.58^{\mathrm{ns}}$ & $1.0118 * *$ & $0.0892^{\mathrm{ns}}$ & $0.0328^{\mathrm{ns}}$ & $46.43^{\mathrm{ns}}$ & $0.0705^{\mathrm{ns}}$ \\
\hline Repetição & 2 & $0.8750^{\mathrm{ns}}$ & $3603.14^{\mathrm{ns}}$ & $0.0378^{\mathrm{ns}}$ & $18.5490^{\mathrm{ns}}$ & $0.0402^{\mathrm{ns}}$ & $48.75^{\mathrm{ns}}$ & $0.1362^{\mathrm{ns}}$ \\
\hline Erro & 14 & 9.2559 & 1189.29 & 0.0615 & 9.0335 & 0.0284 & 45.13 & 0.1868 \\
\hline Total corrigido & 23 & - & - & - & - & - & - & - \\
\hline $\mathrm{CV}(\%)$ & & 14,49 & 16,66 & 2,59 & 22,69 & 25,72 & 13,57 & 21,19 \\
\hline
\end{tabular}

\section{Número de folhas}

Não houve efeito significativo dos tratamentos aplicados para a variável número de folhas, não sendo estas afetadas pela salinidade (NS), nem apresentando diferença entre as cultivares $(\mathrm{C})$; embora não tenham apresentado diferença estatística para nenhum dos fatores estudados, observou-se um perfeito ajuste dos dados ao modelo de regressão quadrática, resultando na equação $\mathrm{NF}=16,482$ $+3,1108 \mathrm{x}-0,3744^{\mathrm{ns}} \mathrm{x}^{2}$ e coeficiente de determinação $\mathrm{R}^{\mathbf{2}}=1$, com coeficiente de variação de $14,49 \%$, que encontra-se dentro do aceitável para pesquisa em ambiente protegido, que segundo classificação de (PIMENTEL, 1985) apresenta média dispersão dos dados.

O resultado apresentado está em consonância com os resultados encontrados por (ANDRIOLO et al., 2005), onde constatou-se que não houve diferença significativa no número de folhas da alface em diferentes níveis de $\mathrm{CE}_{\mathrm{SN}}$ para as condições em que a pesquisa foi desenvolvida. (PAULUS et al., 2012) confronta o resultado pois observou efeito da salinidade sobre o número de folhas da cultivar Verônica sob cultivo hidropônico. 
No que se refere à tolerância da cultivar ao estresse salino, (MAGALHÃES et al., 2010) estudando diferentes cultivares de alface em cultivo hidropônico em condições salinas, também não encontrou diferenças significativas entre a cultivares para esta variável. Esse efeito pode ser atribuído ao sistema de cultivo utilizado, tendo em vista que no cultivo hidropônico há ausência do potencial mátrico, favorecendo a absorção de água pelas plantas devido aumentar o potencial total de água disponível (SOARES, 2007); este fato minimiza os efeitos do potencial osmótico, o que pode justificar a planta não ter sido afetada significativamente pelos sais.

\section{Fitomassa das folhas}

Acerca da fitomassa fresca das folhas (FFF), verificou-se efeito significativo ( $\mathrm{p}<$ $0,01)$ apenas para o fator salinidade (NS), não ocorrendo efeito significativo para a cultivar

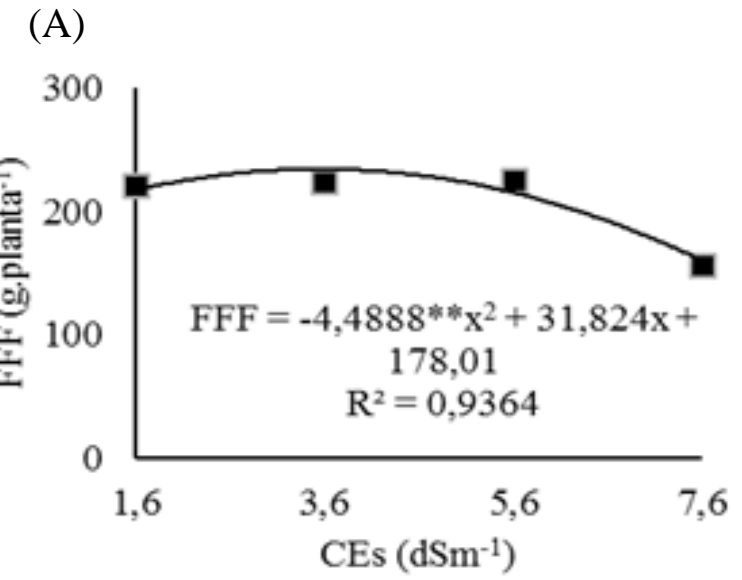

(C) e nem interação entre os fatores (NS x C), aos 14 DAT (Tabela 1). A equação de regressão que melhor se ajustou aos dados FFF em função da salinidade da solução nutritiva foi a quadrática $\left(\mathrm{R}^{2}=0,9364\right)$, a partir da qual definiu-se o ponto de máxima produção de matéria fresca das folhas em CESN de $3,5 \mathrm{dS} \mathrm{m}^{-}$ 1 , com 234,40 g planta ${ }^{-1}$, o acúmulo de fitomassa foi prejudicado para valores acima do ponto máximo encontrado, apresentando decréscimo de 31,48\% para $\mathrm{CE}_{\mathrm{SN}}$ de $7,6 \mathrm{dS} \mathrm{m}^{-}$ ${ }^{1}$ (Figura 1A).

Para a relação entre as cultivares, o delineamento estatístico utilizado demonstrou que o efeito da salinidade foi semelhante para ambas, mas em valores absolutos, observou-se que a cultivar Alcione (C2) foi a que apresentou as maiores médias em relação à cultivar Valentina (C1) em todos os níveis salinos (Figura 1B).

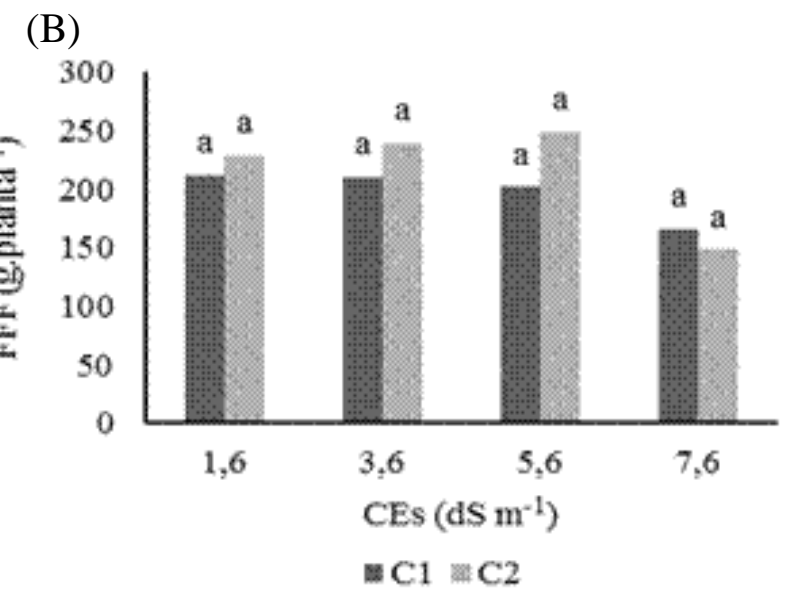

Figura 1. Fitomassa fresca das folhas (FFF) da alface em função da condutividade elétrica da solução nutritiva (A); comparação de médias entre a cultivar Valentina (C1) e Alcione (C2) (B), para 14 DAT.

Rebouças et al., (2013), também relatou influência significativa da salinidade da água de irrigação na fitomassa fresca de folhas de coentro sob cultivo hidropônico, ocasionando diminuição desta variável de 0,48 à 0,13 para as condutividades de 2,55 até a 12,34 $\mathrm{dS} \mathrm{m}^{-1}$, respectivamente. Assim como (HEIDARI, 2012) e (BIONE et al., 2014) que constataram, trabalhando com manjericão sob cultivo hidropônico, redução significativa da massa de matéria fresca ao utilizar solução nutritiva salinizada.

Para a variável fitomassa seca das folhas (FSF) da alface, constatou-se efeito significativo $(\mathrm{p}<0,01)$ entre os diferentes níveis salinos (NS), assim como entre as cultivares $(\mathrm{C})$ estudadas, e interação entre os fatores (NS x S), aos 14 DAT. O modelo quadrático foi o que melhor se ajustou aos dados da cultivar Valentina (C1), apresentando um coeficiente de determinação $\mathrm{R}^{2}=0,9415$ (Figura 2A). Para cultivar Alcione (C2), o efeito da interação resultou na equação de regressão $\mathrm{C} 2=-0,1612 * * \mathrm{x}^{2}+1,5615 \mathrm{x}+$ 6,8004 com coeficiente de determinação $\mathrm{R}^{2}=$ 0,4726 .

Por intermédio do teste de comparação de médias para FSF, verificou-se diferença 
significativa entre as cultivares, onde os maiores valores foram obtidos para o nível de

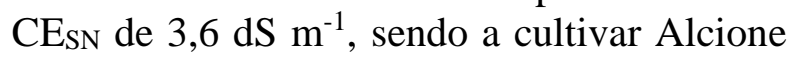
(C2) a que obteve maior valor de FSF com $11,28 \mathrm{~g}$ e a cultivar Valentina (C1) 10,13 g

(A)

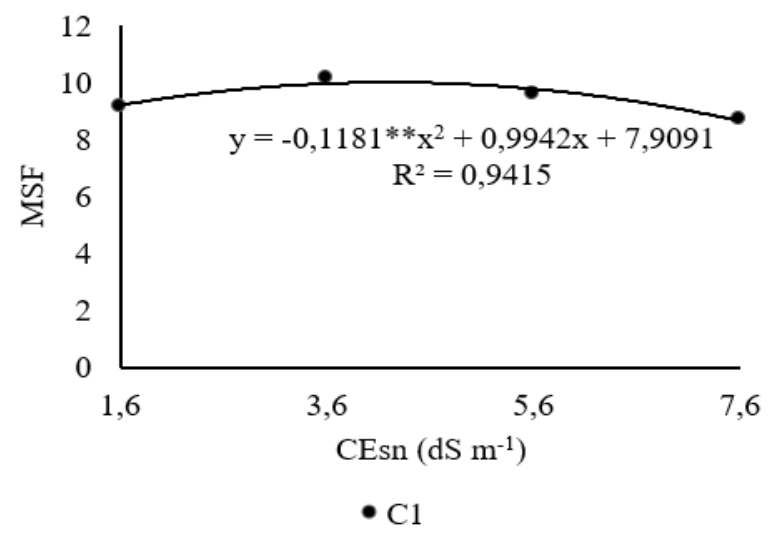

(Figura 2B); a salinidade de 5,6 e $7,6 \mathrm{dS} \mathrm{m}^{-1}$ provocou decréscimo médio percentual de aproximadamente 10,56 e $14,11 \%$, respectivamente.

(B)

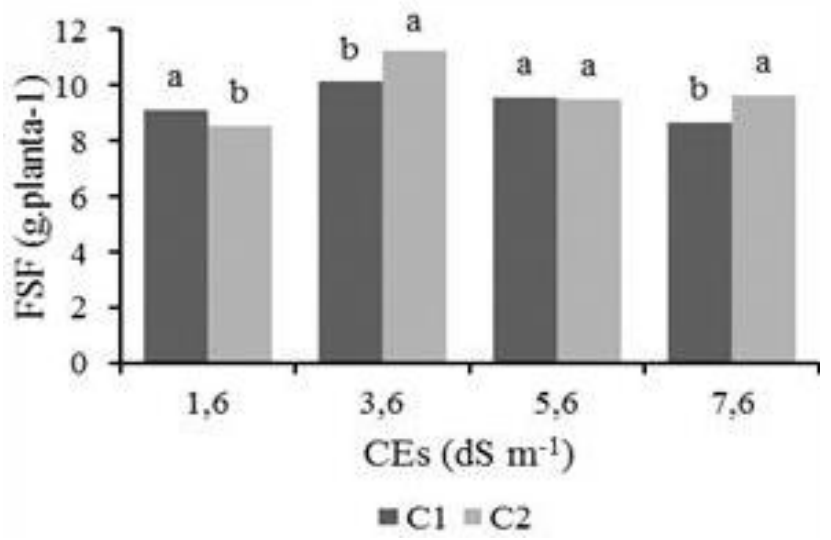

Figura 2. Fitomassa seca das folhas (FSF) da alface em função da condutividade elétrica da solução nutritiva para cultivar Valentina (C1) (A); comparação de médias entre a cultivar Valentina (C1) e Alcione (C2) (B), para 14 DAT.

Segundo Tester e Davenport (2003), o efeito osmótico provocado pela salinidade e o desequilíbrio iônico causado pelo excesso de $\mathrm{Na}^{+}$e $\mathrm{Cl}^{-}$ocasiona o fornecimento inadequado de nutrientes, o que pode levar a diminuição da fitomassa fresca e seca de algumas plantas. Essas perdas ainda podem ser consequência do potencial osmótico da solução nutritiva salinizada, pois nestas condições ocorre a inibição da absorção de água e da capacidade fotossintética das plantas devido a fatores como desidratação das membranas celulares, toxicidade por sais, redução do suprimento de $\mathrm{CO}_{2}$, e alterações nas atividades enzimáticas (IYENGAR; REDDY, 1996).

\section{Fitomassa do caule}

Observou-se efeito significativo ( $\mathrm{p}<$ 0,01) dos níveis salinos (NS) para fitomassa fresca do caule (FFC), no entanto, não houve diferença estatística significativa para a cultivar $(C)$ e nem interação entre os fatores (NS x C) aos 14 DAT. A equação de regressão que melhor se ajustou a resposta da cultura para esta variável foi a quadrática, apresentando um coeficiente de determinação $\mathrm{R}^{2}=0,9934$ (Figura 3). É possível observar os efeitos deletérios da salinidade para esta variável, onde houve uma tendência de diminuição no acúmulo de FFC de $8,57 \%$ a partir do nível de salinidade de $3,6 \mathrm{dS} \mathrm{m}^{-1}$, decrescendo progressivamente para 20,42 e 49,05\% diante do incremento para os níveis de 5,6 e 7,6 dS m ${ }^{-1}$, respectivamente. Embora não haja diferença significativa entre as cultivares, em valores absolutos a fitomassa fresca do caule da cultivar Alcione (C2) obteve menor acúmulo de fitomassa para todos os níveis de sais, obtendo as menores médias em relação a cultivar Valentina (C1). 


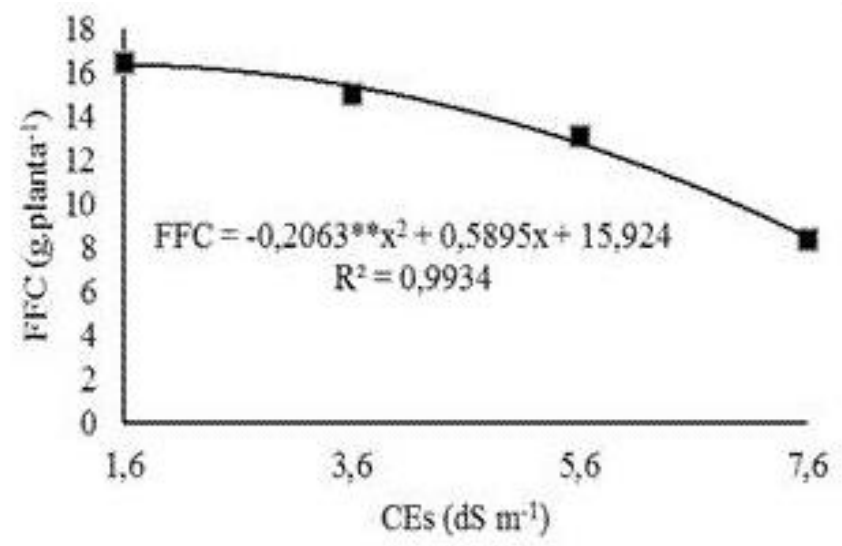

Figura 3. Fitomassa fresca do caule (FFC) da alface em função da condutividade elétrica da solução nutritiva, para 14 DAT.

A fitomassa seca do caule não apresentou diferença estatística para nenhum dos fatores avaliados; no entanto, as médias se ajustaram ao modelo quadrático de regressão, resultando na equação $\mathrm{FSC}=-0,0081^{\mathrm{ns}} \mathrm{x}^{2}+$ $0,0383 \mathrm{x}+0,6891 \mathrm{e}$ coeficiente de determinação $\mathrm{R}^{2}=0,9333$ indicando coerência nos dados coletados, assim como o coeficiente de variação de $25,72 \%$ que encontra-se dentro do aceitável para pesquisa em ambiente protegido (PIMENTEL, 1985).

Rebouças et al., 2013 corrobora com os resultados deste estudo, pois identificou decréscimo na fitomassa fresca do caule de 0,62 para 0,15 g planta $^{-1}$ quando submetidas as condutividades de 2,55 e 12,34 dS m$~ m^{-1}$, respectivamente. $\mathrm{O}$ autor também reporta que a fitomassa do caule não apresentou diferença significativa para o incremento salino, muito embora tenha sido observado, conforme o estudo atual, um decréscimo linear desta variável.

O declínio significativo desta variável pode ser justificado segundo TAIZ E ZEIGER (2009), devido à elevada concentração de sais da solução, que atua desfavorecendo o processo fisiológico e consequentemente, inibindo a atividade meristemática e alongamento celular das plantas.

\section{Fitomassa fresca parte aérea}

A análise de variância mostrou que houve efeito significativo $(\mathrm{p}<0,01)$ dos níveis salinos (NS) para fitomassa fresca da parte aérea (FFPA), mas as cultivares (C) não diferiram estatisticamente entre si e não houve interação entre os fatores (NS x C), aos 14
DAT. Os dados se ajustaram a equação de regressão quadrática, apresentando um coeficiente de determinação $\mathrm{R}^{2}=0,9434$ (Figura 4).

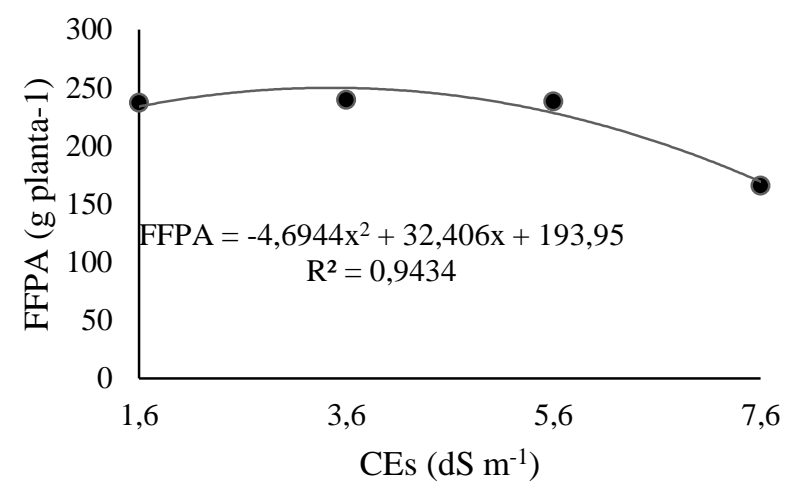

Figura 4. Fitomassa fresca da parte aérea (FFPA) da alface em função da condutividade elétrica da solução nutritiva para 14 DAT.

Essa variável apresentou comportamento semelhante a fitomassa fresca da folhas, onde o ponto máximo de acúmulo de fitomassa fresca na parte aérea foi na condutividade de 3,5 dS m${ }^{-1,}$ com 249,86 g planta ${ }^{-1}$, enquanto na maior salinidade de $7,6 \mathrm{ds} \mathrm{m}^{-1}$ esse acúmulo foi de 169,08 g planta $^{-1}$, ou seja, a FFPA declinou $32,33 \%$ com incremento salino.

\section{Fitomassa das raízes}

Para a variável fitomassa fresca das raízes (FFR) e fitomassa seca das raízes (FSR) da alface, não identificou-se efeito estatístico significativo para os diferentes níveis de salinidade, nem efeito da interação para 14 DAT; muito embora os dados tenham se ajustado a equação de regressão quadrática, 
com coeficientes de determinação $\mathrm{R}^{2}=0,9652$ para fitomassa fresca (Figura $5 \mathrm{~A}$ ), e $\mathrm{R}^{2}=$ 0,9671 para fitomassa seca da raiz (Figura 5B),

(A)

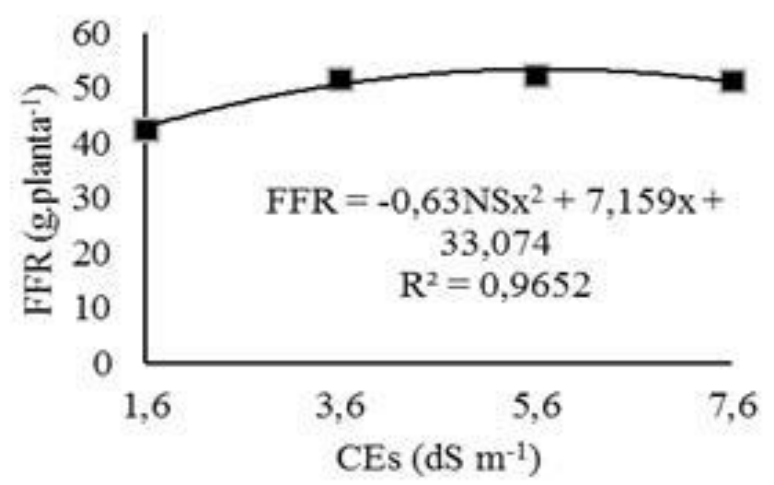

e coeficiente de variação de 13,57 e $21,19 \%$, respectivamente, mostrando a confiabilidade dos dados coletados.

(B)

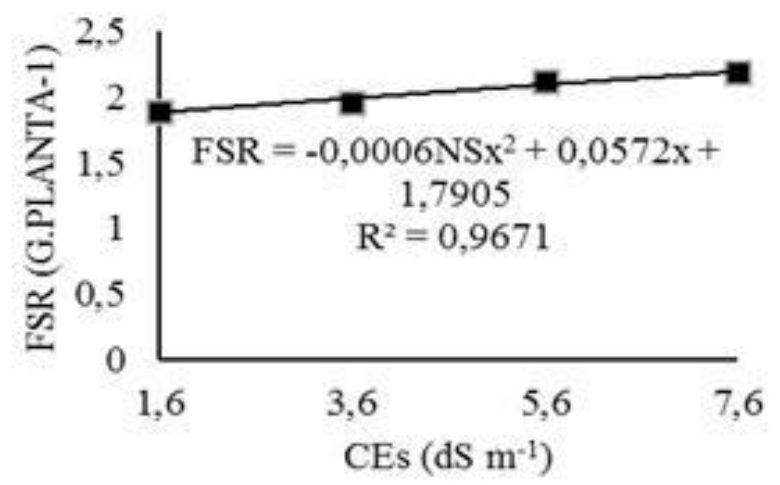

Figura 5. Fitomassa fresca das raízes (FFR) (a) e fitomassa seca das raízes (FSR) (b) da alface em função da condutividade elétrica da solução nutritiva, para 14 DAT.

Segundo (MUNNS, 1993), o crescimento do sistema radicular das culturas geralmente é menos afetado do que a parte aérea, logo essa resposta é comum em plantas submetidas ao estresse salino.

Esse desempenho pode estar associado a um ajustamento osmótico mais rápido e uma perda de turgor mais lenta das raízes, quando equiparada com a parte aérea (SHALHEVET et al., 1995).

Paulus et al., (2010), trabalhando com alface sob cultivo hidropônico utilizando água salina reporta que o efeito da salinidade sobre as raízes é menor se comparado com a parte aérea da alface em hidroponia; corroborando com o estudo atual onde as raízes não foram afetadas significativamente pelo incremento salino.

Com relação às cultivares estudadas, observou-se efeito significativo ( $p<0,01$ ) entre elas apenas para a variável fitomassa fresca da raiz (Figura 6), sendo a cultivar Alcione (C2) a que apresentou maiores médias em todos os níveis de salinidade em relação a cultivar Valentina (C1), visto que esta última apresentou decréscimos percentuais de FFR de $22,23,22,38,22,43$ e $2,74 \%$ para os níveis 1,6 , 3,6, 5,6 e 7,6 dS m $\mathrm{m}^{-1}$, respectivamente, se comparada à Alcione (C2).

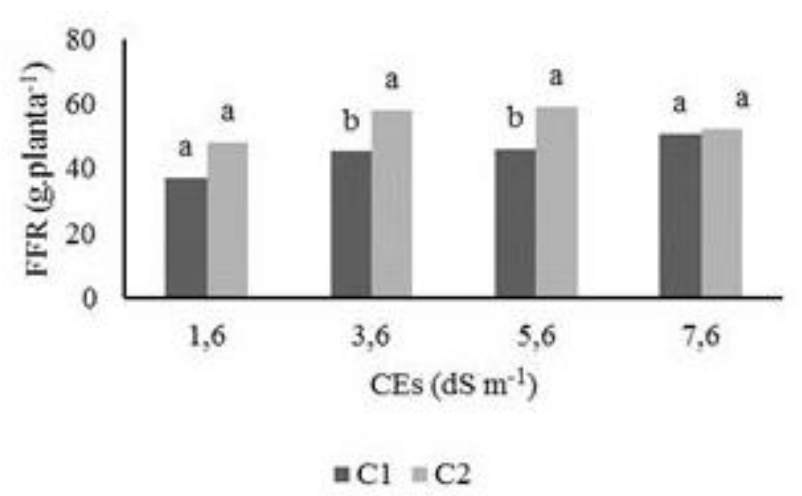

Figura 6. Comparação de médias entre as cultivares Valentina (C1) e Alcione (C2) em função da condutividade elétrica da solução nutritiva, para 14 DAT.

Provavelmente, tal diferença entre as cultivares ocorreu devido as suas características genéticas de adaptação ao estresse salino, que varia entre as espécies cultivadas e entre os genótipos (AKTAS et al., 2006). Yoshida (2002), destaca que alguns genótipos possui aptidão de excluir o $\mathrm{Na}$ das raízes em meio salino, contribuindo para aumentar a relação $\mathrm{K} / \mathrm{Na}$ e expressar sua alta tolerância aos sais.

\section{CONCLUSÕES}

1. Foi tecnicamente viável produzir alface no sistema hidropônico NFT 
para $\mathrm{CE}_{\mathrm{SN}}$ de até $3,5 \mathrm{dS} \mathrm{m} \mathrm{m}^{-1}$, considerando a fitomassa fresca das folhas como a variável mais relevante para comercialização do produto;

2. As cultivares estudadas apresentaram comportamento estatístico semelhante quando submetidas à salinidade, no entanto, em valores absolutos a cultivar Alcione se mostrou mais tolerante para todos os níveis as quais foram submetidas;

3. Embora a salinidade tenha afetado significativamente algumas variáveis analisadas das plantas de alface, não identificou-se sintomas deletérios que pudessem comprometer a comercialização do produto.

\section{REFERÊNCIAS}

ABCSEM. (2013). Associação Brasileira de Comércio de Sementes e Mudas. Projeto para o levantamento dos dados socioeconômicos da cadeia produtiva de hortaliças no Brasil. Campinas, São Paulo, URL http://www.abcsem.com.br/upload/arquivos. AKTAS, H,. ABAK, K., CAKMAK, I. Genotypic variation in the response of pepper to salinity. Scientia Horticulturae, v. 110, n. 3: p. 260-266, 2006.

ALVES, M.S., SOARES, T.M., SILVA, L.T., FERNANDES, J.P., OLIVEIRA, M.L., PAZ, V.P. 2011. Estratégias de uso de água salobra na produção de alface em hidroponia NFT. Revista Brasileira de Engenharia Agrícola e Ambiental, v. 15, n. 5, p. 491-498, 2011.

ANDRIOLO, J.L., LUZ, G.L.D., WITTER, M.H., GODOI, R.D.S., BARROS, G.T., BORTOLOTTO, O.C. Growth and yield of lettuce plants under salinity. Horticultura Brasileira, v. 23, n. 4, p. 931-934, 2005.

BIONE, M.A., PAZ, V.D.S., SILVA, F., RIBAS, R.F., SOARES, T.M. Crescimento e produção de manjericão em sistema hidropônico NFT sob salinidade. Revista Brasileira de Engenharia Agrícola e Ambiental, v. 18, n. 12, p. 1228-1234, 2014.
CAVALCANTE, L.F., REBEQUI, A.M., DE SENA, G.S.A., NUNES, J.C. Irrigação com águas salinas e uso de biofertilizante bovino na formação de mudas de pinhão-manso. Irriga, v.16, n.3, p. 288-300, 2011.

CRUZ, W.B.; MELO, F.A.C.F de. Zoneamento químico e salinização das águas subterrâneas do Nordeste do Brasil. In: Boletim de Recursos Naturais. SUDENE (Superintendência do Desenvolvimento do Nordeste), v.7, n.1/4, p. 7-40, 1969.

FERREIRA, D.F. 2014. SISVAR: a Guide for its Bootstrap procedures in multiple comparisons. Ciência e Agrotecnologia, v. 38, n. 2, p. 109-112, 2014.

FURLANI, P.R., SILVEIRA, L.C.P., BOLONHEZI, D., FAQUIN, V. Cultivo Hidropônico de Plantas: Parte 1 - Conjunto hidráulico. Ribeirão Preto, São Paulo, 2009. URL http://www.infobibos.com.

FURLANI, P.R., SILVEIRA, L.C.P., BOLONHEZI, D., FAQUIN, V. Cultivo hidropônico de plantas. Campinas: Instituto Agronômico de Campinas. Boletim técnico, v.180, 1999, p.52

HEIDARI, M.. Effects of salinity stress on growth, chlorophyll content and osmotic components of two basil (Ocimum basilicum L.) genotypes. African Journal of Biotechnology, v.11, n.2, p. 379-384, 2012.

IYENGAR, E. R. R.; REDDY, M. P. Photosynthesis in highly salt tolerant plants. Handbook of photosynthesis. Marshal Dekar, Baten Rose, USA, v. 909, 1996.

MACIEL, M.P., SOARES, T.M., GHEYI, H.R., REZENDE, E.P., OLIVEIRA, G.X. Produção de girassol ornamental com uso de águas salobras em sistema hidropônico NFT. Revista Brasileira de Engenharia Agrícola e Ambiental, v.16, n.2, p. 165-172, 2012.

MAGALHÃES, A.G., MENEZES, D., RESENDE, L.V., BEZERRA NETO, E. 
Desempenho de cultivares de alface em cultivo hidropônico sob dois níveis de condutividade elétrica. Horticultura Brasileira, v.28, n.3, p. 316-320, 2010.

MUNNS, R. Physiological processes limiting plant growth in saline soils: some dogmas and hypotheses. Plant, Cell \& Environment, v.16, n.1, p. 15-24, 1993.

DE OLIVEIRA, F.D.A., MARIA, J.D.O., DE MEDEIROS, J.F., MARACAJÁ, P.B., DE OLIVEIRA, M.K. Desempenho de cultivares de alface submetidas a diferentes níveis de salinidade da água de irrigação. Revista Brasileira de Engenharia Agrícola e Ambiental, v.15, n.8, p. 771-778, 2011.

PAULUS, D., DOURADO NETO, D., FRIZZONE, J.A., SOARES, T.M. Produção e indicadores fisiológicos de alface sob hidroponia com água salina. Horticultura Brasileira, v.28, n.1, p. 29-35, 2010.

PAULUS, D., PAULUS, E., NAVA, G.A., MOURA, C.A.. Crescimento, consumo hídrico e composição mineral de alface cultivada em hidroponia com águas salinas. Revista Ceres, v.59, n.1, p. 110-117, 2012.

PIMENTEL, F.G. Curso de Estatística Experimental. Nobel, São Paulo, Brasil. 1985. 467p.

REBOUÇAS, J.R.L., NETO, M.F., SILVA D.N., SOUZA NETO, O.N., DINIZ, A.A., LIRA, R.B. Cultivo hidropônico de coentro com uso de rejeito salino. Irriga, v.18, n.4, p. 624-634, 2013.

RODRIGUES, R.R., BERTOSSI A.P.A., GARCIA G. DE O., ALMEIDA J.R., SILVA E.A. Salinidade no desenvolvimento de cultivares de alface. Revista Agrarian Academy, v.2, n.4, p. 70-81, 2015.

SANTOS, A.N., SOARES, T.M., SILVA, E.D.F., SILVA, D.J., MONTENEGRO, A.A. Cultivo hidropônico de alface com água salobra subterrânea e rejeito da dessalinização em Ibimirim, PE. Revista Brasileira de Engenharia Agrícola e Ambiental, v.14, n.9, p. 961-969, 2010.

SANTOS, O. S, dos. (Org.). Cultivo hidropônico. Santa Maria: UFSM: Colégio politécnico, 2012, P.264.

SILVA, E.N., SILVEIRA, J.A.G., RODRIGUES, C.R.F., LIMA, C.S., VIÉGAS, R.A. Contribuição de solutos orgânicos e inorgânicos no ajustamento osmótico de pinhão-manso submetido à salinidade. Pesquisa Agropecuária Brasileira, v.44, n.5, p. 437-445, 2010.

SHALHEVET, J., HUCK, M.G., SCHROEDER, B.P. Root and shoot growth responses to salinity in maize and soybean. Agronomy Journal, v.87, n.3, p.512-516, 1995.

SOARES, T.M. 2007. Utilização de águas salobras no cultivo da alface em sistema hidropônico NFT como alternativa agrícola condizente ao semiárido brasileiro. 2007. Tese (Doutorado em irrigação e drenagem). Escola Superior de Agricultura "Luiz de Queiroz, Piracicaba, Brasil.

SOARES, T.M., DUARTE, S.N., SILVA, E.D.F., JORGE, C.A. Combinação de águas doce e salobra para produção de alface hidropônica. Revista Brasileira de Engenharia Agrícola e Ambiental v.14, n.7, p.705-714, 2010.

TAIZ, L., ZEIGER, E. Plant physiology. Porto Alegre: Artmed, 2009, 719p.

TESTER, M., DAVENPORT, R.. Na+ tolerance and $\mathrm{Na}+$ transport in higher plants. Annals of botany, v.91, n.5, p.503-527, 2003.

YOSHIDA, K. Plant biotechnology genetic engineering to enhance plant salt tolerance. Journal of bioscience and bioengineering, v.94, n.6, p. 585-590, 2002. 